\title{
Types of Lasers and Their Applications in Pediatric Dentistry
}

\author{
${\text { Bahareh Nazemisalman' }{ }^{1}, \text { Mahya Farsadeghi }^{2} \text {, Mehdi Sokhansanj }}^{2}$ \\ 'Department of Pediatrics, School of Dentistry, Zanjan University of Medical Sciences, Zanjan, Iran \\ ${ }^{2}$ School of Dentistry, Zanjan University of Medical Sciences, Zanjan, Iran
}

\section{Correspondence to}

Mahya Farsadeghi, DDS; Schoo

of Dentistry, Zanjan University of Medical Sciences, Zanjan, Iran. Tel: 024-33337017: Fax: 024-33445550; Email: mahyafarsadeghi@gmail.com

Published online 28 June 2015

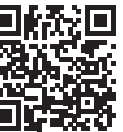

\section{Introduction}

Laser technology has been recently introduced to the field of medicine in order to address the diagnostic and therapeutic needs of patients faster and more efficiently. ${ }^{1}$ The stimulated emission theory discussed by Einstein ${ }^{2}$ in 1916 later resulted in development of the first working laser by Maiman ${ }^{3}$ Laser stands for light amplification by stimulated emission of radiation. ${ }^{4}$ Soon after its advent, researchers attempted to use it for dental purposes due to its unique characteristics. ${ }^{5}$ Since contemporary dentistry is based upon the use of minimally invasive procedures, laser can serve as a favorable alternative to drilling due to having less pain, sound and vibration. Maintaining a dry environment enhances the clinician's view of the working area and results in a better outcome. Moreover, substitution of sharp dental instruments with laser attracts more patients to dental clinics. ${ }^{6}$ However, laser therapy has some shortcomings as well such as high cost, difficult accessibility, its dangerous nature if safety measures are not followed, not being applicable in all fields of dentistry, inability to remove metal restorations and thermal damage to soft tissues.?

Laser was first used for soft tissue incision. But, the new generation of lasers with their special function on water molecules can be used for ablation of dental hard tissue as well. Due to recent advances in laser applications in most dental fields, it is now efficiently used for caries preven- tion, diagnosis and treatment. ${ }^{8}$

Pedodontists try to create a pleasant memory of the first dental visit for children by using novel, minimally invasive technologies to help the child establish good dental habits. ${ }^{9}$ Having a less painful first dental experience through the use of a modern technology like laser would be an efficient preventive and therapeutic strategy. Laser can be successfully used for diagnosis of oral and dental conditions, treatment of the hard and soft tissues and prevention of rapidly progressive oral and dental conditions in children. ${ }^{10}$

Considering the importance of oral and dental health in physical health status of children, this study aimed to review different types of lasers and their applications in pediatric dentistry.

\section{History of Laser \\ In May 16, 1960, laser was developed by Theodore Maiman $^{3}$ using a synthetic ruby crystal. The first appli- cation of laser was for the diagnosis and treatment of skin conditions. Later, it was used for endoscopic surgery and then in ophthalmology. ${ }^{11}$ The first application of laser in dentistry was for oral soft tissue surgery. ${ }^{12}$ Laser served as a scalpel by cutting or ablating the tissue using the ener- gy of laser light. Its mechanism of action is via intensified light generated by the stimulation of a synthetic material inside a light chamber. The energy is emitted uniformly}


and continuously towards the target organ without directly contacting it. ${ }^{6}$ Lasers are often named after their active medium generating photons. Dental lasers have variable wavelengths and run in continuous-wave, pulsed or running pulsed mode. Wavelengths in the range of 193-10600 $\mathrm{nm}$ are applicable in medicine and dentistry. The wavelength of laser determines its clinical application and type of laser device. ${ }^{12}$

Based on their specific applications, lasers are divided into 4 main groups of solid state lasers, liquid lasers, gas lasers and semi-conductor lasers. Gas lasers have a simpler design compared to other types. ${ }^{13}$ Relative dispersion of the emitting atoms in gases creates a relatively homogenous environment. These are continuous-wave lasers. The most important characteristic of liquid lasers is their ability to change their frequency. Lightness and high optical output power are among the characteristics of semiconductor lasers explaining their popularity. ${ }^{14}$

\section{Types of Lasers and Their Applications in Dentistry}

The most commonly used lasers in dentistry include holmium yttrium aluminium garnet (HO:YAG), neodymium-doped yttrium aluminium garnet (Nd:YAG), carbon dioxide laser $\left(\mathrm{CO}_{2}\right)$, erbium-doped yttrium aluminum garnet (Er:YAG), neodymium doped yttrium aluminum perovskite (Nd:YAP), gallium arsenide (GaAs) (diode), erbium, chromium doped yttrium scandium gallium garnet (Er-Cr:YSGG) and argon lasers. Clinical applications of lasers in dentistry include soft and hard tissue surgery, root planning (elimination of calculus from the root surfaces), cavity preparation in the enamel and dentin, detection of dental caries, cleaning the root canal system, etching, caries prevention by changing the crystalline structure of enamel, tooth whitening, periodontal therapy and peri-implantitis treatment. ${ }^{8}$ Table 1 presents different types of dental lasers and their applications.

\section{Application of Laser in Pediatric Dentistry}

It is important to motivate children for dental visits in order to prevent oral and dental conditions. Thus, aside from dental principles, pedodontists must learn the new technologies. ${ }^{13}$ Laser technology provides an opportunity for more efficient diagnosis and treatment of oral and dental soft and hard tissue conditions in children. Laser therapy is well accepted by the children and parents due to its minimal invasiveness. ${ }^{7}$ Studies have demonstrated that children are more cooperative during restorative, pulpal and surgical treatments using laser, which significantly promotes the quality of care and enhances the process of treatment. Laser seems to soon become the gold standard in pediatric dentistry. ${ }^{15}$ Different types of lasers and their applications in pediatric dentistry are as follows:

\section{Hard Tissue Applications of Laser \\ Caries Detection}

Accurate detection of caries helps the clinicians suitably restore the tooth in shorter time and with less cost. Studies have demonstrated that laser fluorescence (LF) can enhance the accuracy and speed of clinical detection of caries. ${ }^{16,17}$

$\mathrm{LF}$ at a wavelength of $655 \mathrm{~nm}$ (nonablative with red light) can be used as an adjunct for disclosing occlusal caries in primary and permanent teeth and due to its high reliability, predictability and reproducibility, it decreases diagnostic errors. ${ }^{17,18}$ DIAGNOdent is a commercial product using LF technology. An in vitro study demonstrated its superior efficacy for disclosing occlusal dentin caries in primary teeth in comparison to visual inspection, probing and radiography. ${ }^{19}$ Some previous studies have reported equal or higher accuracy of LF and bitewing radiography for detection of caries and cavitation of primary teeth in proximal areas. ${ }^{20,21}$ However, its efficient performance depends on the depth of carious lesion. It can more accurately detect dentin compared to enamel caries and does not have much efficacy for detection of initial enamel caries and tooth demineralization. ${ }^{22}$

Argon laser at a wavelength of $488 \mathrm{~nm}$ (blue-green color) is another diagnostic laser that enables detection of caries particularly in the interproximal and occlusal surfaces with the help of fluorescence property. It is also known as quantitative-light induced fluorescence (QLF). ${ }^{1}$ It is more efficient in quantitative detection of demineralization in primary teeth compared to permanent teeth. ${ }^{23}$ Use of QLF enables easy detection of caries beneath the pit and fissure sealants during the routine and periodic examinations. ${ }^{24}$

\section{Caries Prevention}

Resistance of the tooth surface to penetration of cariogenic agents plays an important role in prevention of caries. Erbium and $\mathrm{CO}_{2}$ lasers can be successfully used to increase resistance of a newly erupted permanent tooth in children and adolescents to acid erosion. Studies have demonstrated that $\mathrm{CO}_{2}$ laser at 9600, 9300 and $10600 \mathrm{~nm}$ wavelengths, erbium laser at 2780 and $2940 \mathrm{~nm}$ wavelengths and argon laser can confer resistance to enamel surfaces against caries. ${ }^{25,26}$ Several studies have demonstrated further increase in tooth resistance by simultaneous application of laser and fluoride therapy. For instance, argon laser in conjunction with acidic phosphate fluoride (APF) causes a $50 \%$ decrease in caries depth compared to the use of laser alone..$^{26,27}$

\section{Restoration, Pit and Fissure Sealants}

Laser can also be used for tooth surface preparation prior to the application of pit and fissure sealants. Laser can be applied for conditioning, cleaning and disinfection of pits and fissures as well. ${ }^{28}$ For instance, after ensuring the presence of caries in pits and fissures based on the obtained LF values (between 11-20 to 21-30), erbium laser can be used for fissurotomy and elimination of caries. LF values between 0-10 indicate sound tooth; in this condition, only macro-roughening is performed by erbium laser at lower wavelengths. ${ }^{18}$

Studies have demonstrated that application of laser alone, without acid etching for preparation of enamel pits and fissures results in a subsequently high rate of microleak- 
Table 1. Characteristics of Dental Lasers

\begin{tabular}{|c|c|c|c|}
\hline Laser Type & Wavelength & Mode & Application \\
\hline $\mathrm{CO}_{2}$ & $10600 \mathrm{~nm}$ & Pulse or continuous-wave & $\begin{array}{l}\text { 1. Soft tissue ablation } \\
\text { 2. Gingival contouring for esthetic purposes } \\
\text { 3. Treatment of oral ulcerative lesions } \\
\text { 4. Frenectomy and gingivectomy } \\
\text { 5. Elimination of necrotic epithelial tissue during regenerative periodontal } \\
\text { surgeries }\end{array}$ \\
\hline $\mathrm{Nd}: Y A G$ & $1064 \mathrm{~nm}$ & Pulse & $\begin{array}{l}\text { 1. Root canal therapy: Helps eliminate pathogenic microorganisms and debris } \\
\text { from the root canal } \\
\text { 2. Extensive periodontal surgery and scaling to eliminate necrotic tissues and } \\
\text { pathogenic microorganisms } \\
\text { 3. Caries removal }\end{array}$ \\
\hline Er:YAG & $2940 \mathrm{~nm}$ & Pulse & $\begin{array}{l}\text { 1. Caries removal } \\
\text { 2. Cavity preparation in enamel and dentin } \\
\text { 3. Root canal preparation }\end{array}$ \\
\hline $\mathrm{Er}, \mathrm{Cr}: \mathrm{YSGG}$ & $2780 \mathrm{~nm}$ & Pulse & $\begin{array}{l}\text { 1. Enamel etching } \\
\text { 2. Caries removal } \\
\text { 3. Cavity preparation } \\
\text { 4. Bone ablation without over-heating, melting or changing the calcium and } \\
\text { phosphorus ratios } \\
\text { 5. Root canal preparation }\end{array}$ \\
\hline Argon & $572 \mathrm{~nm}$ & Pulse or continuous & $\begin{array}{l}\text { 1. Polymerization of restorative resin materials } \\
\text { 2. Tooth bleaching } \\
\text { 3. Elimination of necrotic tissue and gingival contouring } \\
\text { 4. Treatment of oral lesions such as recurrent aphthous ulcers or herpetic } \\
\text { lesions } \\
\text { 5. Frenectomy and gingivectomy }\end{array}$ \\
\hline Diode & 810 or $980 \mathrm{~nm}$ & Pulse or continuous-wave & $\begin{array}{l}\text { 1. Proliferation of fibroblasts and enhancing the healing of oral lesions or } \\
\text { surgical wounds } \\
\text { 2. Frenectomy and gingivectomy } \\
\text { 3. Correcting the gingival contouring for esthetic purposes }\end{array}$ \\
\hline HO:YAG & $2100 \mathrm{~nm}$ & Pulse & $\begin{array}{l}\text { 1. Gingival contouring } \\
\text { 2. Treatment of oral lesions } \\
\text { 3. Frenectomy and gingivectomy }\end{array}$ \\
\hline
\end{tabular}

age. ${ }^{29}$ Thus, laser application does not eliminate the need for enamel acid etching. ${ }^{30}$ On the other hand, some researchers reported that application of laser in conjunction with acid etching resulted in microleakage in $80 \%$ of specimens due to the formation of enamel cracks and debris at the sealant-enamel interface. They have recommended the use of argon laser for curing of the sealant material at the enamel-sealant interface to possibly increase enamel resistance to acids. ${ }^{1}$ However, some other studies found no difference in the amount of microleakage in acid etching with and without laser for preparation of pits and fissures. ${ }^{31}$ Surface preparation with Er,Cr:YSGG laser prior to fissure sealant application has demonstrated to have no effect on increasing resistance to microleakage in primary teeth. ${ }^{32}$

\section{Endodontics}

Laser technology can be used for pulpotomy, pulpectomy and pulp coagulation as an alternative to formocresol, which is used for pulpotomy of primary teeth and has carcinogenic and mutagenic properties..$^{33}$ Researchers have reported superior clinical results in pulpotomy of primary teeth with $\mathrm{CO}_{2}$ laser compared to formocresol ${ }^{34}$ and demonstrated that pulpal inflammation decreased after laser therapy and had a reverse correlation with the amount of energy received. ${ }^{33}$

Efficient use of laser technology in cleaning and shaping of the root canal system has also been demonstrated. For instance, Er,Cr:YSGG laser has cleaning and shaping efficacy similar to that of rotary instruments and superior to that of hand instruments. Moreover, this laser acts faster than the afore-mentioned 2 techniques. ${ }^{35}$

Application of Er:YAG, Er,Cr:YSGG and $\mathrm{CO}_{2}$ lasers for pulp coagulation has also shown more favorable results after 2 years in comparison with calcium hydroxide. ${ }^{34,36}$ Studies have indicated that vital pulp therapy and pulp hemostasis after pulpotomy with the help of $\mathrm{CO}_{2}$ laser had 98.1\% clinical success and $91.8 \%$ radiographic success. ${ }^{34}$ However, other studies on lasers such as Nd:YAG laser for pulpotomy of primary teeth have reported $71.42 \%$ clinical and $85.71 \%$ radiographic success during 12 months, and appear to be unsuccessful in comparison with formocresol with a clinical and radiographic success rate of $90.47 \%$ during the same time period. ${ }^{37}$

\section{Soft Tissue Applications of Laser}

Laser provides an opportunity for safe treatment of periodontal disease in children without causing allergic reactions or bacterial resistance. ${ }^{11}$ All wavelengths of laser enable gingivectomy, gingivoplasty and operculectomy without the need for local anesthesia and without bleeding. ${ }^{38}$ Enhancement of tooth eruption, elimination of abnormal gingival lesions due to improper tooth movements, treatment of drug-induced gingival hyperplasia, resection of fibroma, aphthous lesions, herpes labialis, mucocele and pyogenic granuloma and also esthetic procedures are 
among other applications of lasers. ${ }^{14,39}$

Er:YAG laser can be used for frenectomy in infants with tight maxillary frenums or for upper and lower frenectomy in infants with severe ankyloglossia. ${ }^{40}$

$\mathrm{CO}_{2}$ laser can be used for surgical resection of vascular tumors in the oral cavity and gingival enlargement due to the use of cyclosporine. This laser has the advantages of disinfection and coagulation in comparison with surgical scalpel. ${ }^{41,42}$

Micro-gingival surgery with laser can be done for treatment of traumatic injuries to unerupted teeth. ${ }^{33}$ Erbium laser enables removal of a part of gingiva covering a cervical carious lesion. ${ }^{18}$

Researchers have also demonstrated that low level laser therapy (LLLT) accelerates orthodontic tooth movement. ${ }^{43}$ Laser/light emitting diode (LED) can also be used to shorten the course of disease and enhance healing of children suffering from herpetic lesions and primary herpetic stomatitis. ${ }^{11}$

\section{Traumatology and Vitality Testing}

Trauma to the teeth can have adverse short-term and long-term consequences and may compromise pulp vitality. Laser doppler flowmetry (LDF) indicates the pulp blood flow (PBF) and can be used to assess pulp vitality. This method is accurate, noninvasive, reproducible, reliable and painless and is well tolerated by children. It appears that LDF can also be helpful for monitoring of revascularization and mobile teeth. ${ }^{44}$

Other applications of laser for traumatized teeth include preparation of the broken edge of injured teeth prior to restoration, exposed pulp coagulation, pulpotomy and pulpectomy (with erbium laser) after trauma, if necessary. Moreover, Er:YAG and Er,Cr:YSGG lasers can be used for fusion and sealing of dentinal tubules in case of fractured teeth or open dentinal tubules. By doing so, the permeability of tubules and the consequent tooth hypersensitivity will decrease. ${ }^{33}$

Soft tissue trauma, facial wounds and swelling can also be alleviated by the application of laser/LED to the area. This method can also be used in severely traumatized areas to decrease post-traumatic discomfort. ${ }^{11}$

\section{Preservation of Pulp Vitality}

Laser irradiation can be used for preservation of pulp vitality. Different wavelengths with $0.5-1 \mathrm{~W}$ power, non-concentrated beam, low frequency and pulse mode without water and for durations less than 10 seconds (in order not to cause coagulation) and with 30 -second intervals (to prevent over-heating of the pulp) can be useful for this purpose. ${ }^{18}$

Use of $808 \mathrm{~nm}$ probe around the root area of traumatized central and lateral incisors in children is considered a successful treatment modality to prevent pulp necrosis. ${ }^{11}$

\section{Disinfection and Decontamination}

Laser technology has beneficial antimicrobial effects as well. An in vitro study demonstrated elimination of $99 \%$ of the bacteria in collagen matrix by the application of diode laser via the photo-activated bacterial disinfection (PAD) method during root canal therapy and caries removal. ${ }^{20}$ However, cleaning and disinfecting the primary root canal system require utmost precision due the complex anatomy of the apex. Special attention must be paid to the penetration depth of laser, which is close to infrared light. ${ }^{33}$

The antimicrobial effect of erbium laser on the root canal system has also been demonstrated. ${ }^{14}$ Alveolar socket decontamination following tooth avulsion is another capability of lasers. ${ }^{33}$

\section{Analgesic Effects, Alleviation of Pain and Discomfort}

Laser increases the pain threshold of patients and decreases the need for local anesthetics. ${ }^{8,45}$ Studies have demonstrated that anesthesia can be achieved by application of laser in near infrared wavelengths (803-980 nm) using non-concentrated mode. This effect can be exerted on the pulp and last for 15 minutes by hyperpolarizing the membrane of nerve fibers. ${ }^{18}$ This technique had a success rate of $50 \%-75 \%$ on primary molar teeth for preparation of class II cavities without anesthetic injection using a 660 nm probe. $^{11}$

$\mathrm{CO}_{2}$ laser can be locally used to relieve pain due to orthodontic forces and LLLT accelerates orthodontic tooth movement with no adverse effect. ${ }^{46,47}$ Laser/LED irradiation around the orthodontic site or temporomandibular joint has been able to successfully alleviate pain. ${ }^{11}$

LLLT of lymph nodes during the eruption of primary or permanent teeth and laser irradiation (4 to $6 \mathrm{~J}$ ) of exposed primary teeth can effectively decrease pain as well. ${ }^{33}$ LLLT can also effectively decrease primary inflammatory response ${ }^{47}$ and 3 to $4 \mathrm{~J}$ dose is suitable to decrease pain and swelling in case of trauma to the lips and anterior teeth. ${ }^{33}$

Exposure of Unerupted Teeth for Orthodontic Purposes For soft tissue removal and exposure of unerupted teeth for orthodontic purposes, Er,Cr:YSGG, Er,YAG, diode and Nd:YAG lasers are used. ${ }^{48}$ Erbium laser is efficient for both soft and hard tissue ablation. But, there is always a risk of enamel damage at the surgical site. However, this risk is nonexistent if diode or Nd:YAG lasers are used due to their specific wavelengths. ${ }^{49}$

\section{Conclusion}

Considering all the aforementioned, laser can be a suitable alternative for many conventional procedures in pediatric dentistry. Diagnosis and removal of caries, pulp therapy, decreasing the risk of infection, swelling and inflammation, reducing bleeding, enhancing soft tissue healing, pain relief and reducing gag reflex are among the applications of laser in pediatric dentistry. Children are often more cooperative when laser is used for dental treatments due to its minimal invasiveness. This results in higher satisfaction of children and their parents and increases the quality of service. Due to the diversity of this subject, further studies are required on the efficacy of laser application for dental procedures particularly in pediatric dentistry. 


\section{References}

1. Martens LC. Laser-assisted Paediatric Dentistry: Review and Outlook. J Oral Laser Appl. 2003;3(4):203209.

2. Gross A, Herrmann W. History of lasers. World J Urol. 2007;25(3):217-220. doi:10.1007/s00345-007-0173-8.

3. Javan A, Bennette WR Jr, Herriot DR. Population inversion and continuous optical maser oscillation in a gas discharge containing a $\mathrm{He} \mathrm{Ne}$ mixture. Physiol Rev. 1961;6:1106-1110. doi:10.1103/physrevlett.6.106.

4. Norbert G, Rene F, Leon V, Frieclrich L. Laser in pediatric dentistry- a review. J Oral Laser Appl. 2005;5:207-209.

5. Statement AoLDP. Access 2001:35.

6. Straussa R, Jonesb G, Wojtkowskic D. A comparison of postoperative pain parameters between $\mathrm{CO}_{2}$ laser and salpel biopsies. J Oral Laser Appl. 2006;8:39-42.

7. Boj JR, Poirier C, Espasa E, Hernandez M, Espanya A. Lower lip mucocele treated with an erbium laser. Pediatr Dent. 2009;31(3):249-252.

8. Boj J. The Future Of Laser Pediatric Dentistry. J Oral Laser Appl. 2005;5:173-7.

9. Widmer R. Implications of child development on the practice of oral care. Compend Contin Educ Dent. 2002;23(3 Suppl 2):4-9.

10. Dean J, Avery D, McDonald R. Dentistry for the Child and Adolescent. 9thed. Boston: Mosby; 2011.

11. Koci E, Almas A. Laser application in dentistry: an evidance-based clinical decision-making update. Pak Oral Dent J. 2009;29(2):409-423.

12. Aoki A, Mizutani K, Tasaki AA, et al. Current status of clinical laser application in periodontal therapy. Gen Dent. 2008;56(7):674-687.

13. Boj J, Hermandez M, Poirier C, Espasa E. Laser: a powerful tool for treatment of pyogenic granuloma. J Cutan Aesthet Surg. 2011;4(2):144-147. doi: 10.4103/0974-2077.85044.

14. Ramazani N, Ahmadi R, Daryaeian M. Oral and dental laser treatment for children: applications, advantages and consideration. J Lasers Med Sci. 2012;3(1):44-49.

15. Ramazani N, Poureslami H, Ahmadi R, Ramazani M. Early childhood caries and the role of pediatricians in its prevention. Iran J Pediatric Soc. 2010;22:11-25.

16. Krause F, Jepsen S, Braun A. Comparison of two laser fluorescence devices for the detection of occlusal caries in vivo. Eur J Oral Sci. 2007;115:252-256. doi:10.1111/j.1600-0722.2007.00456.x.

17. Olivi G, Genovese MD. Laser restorative dentistry in children and adolescents. Eur Arch Paediatr Dent. 2011;12(2):68-78. doi:10.1007/bf03262782.

18. Bengtson AL, Gomes AC, Mendes FM, Cichello LR, Bengtson NG, Pinheiro SL. Influence of examiner's clinical experience in detecting occlusal caries lesions in primary teeth. Pediatr Dent. 2005;27(3):238-243.

19. Lussi A, Francesnut P. Performance of conventional and new methods for the detection of occlusal caries in deciduous teeth. Caries Res. 2003;37:2-7. doi:10.1159/000068226.

20. Lussi A, Zimmerli B, Hellwig E, Jaeggi T. Influence of the condition of the adjacent tooth surface on fluorescence measurements for the detection of approximal caries. Eur J Oral Sci. 2006;114(6):478482. doi:10.1111/j.1600-0722.2006.00410.x.

21. Novaes TF, Matos R, Braga MM, Imparato JC, Raggio DP, Mendes FM. Performance of a pen-type laser fluorescence device and conventional methods in detecting approximal caries lesions in primary teeth-in vivo study. Caries Res. 2009;43(1):36-42. doi:10.1159/000189705.

22. Braga $M$, Nicolau J, Rodriguez CR, Imparato JC, Mendes FM. Laser fluorescence devise does not perform well in detection of early caries lesions in primary teeth: an in vitro study. Oral Health Prev Dent. 2008;6:165-169.

23. Ando M, van Der Veen MH, Schemehron BR, Stookey GK. Comparative study to quantify demineralized enamel in deciduous and permanent teeth using laser and light-induced fluorescence techmiques. Caries Res. 2001;35:464-470.

24. Takamori K, Hokari N, Okumura Y, Watanabe S. Detection of occlusal caries under sealants by use of a laser fluorescence system. J Clin Laser Med Surg. 2001;19:267-271. doi:10.1089/10445470152612008.

25. Apel C. Birker L, Meister J, Weiss C, Gutknecht N. The caries-preventive potential of subablative Er:YAG and Er:YSGG laser radiation in an intraoral model: apilot study. Photomed Laser Surg. 2004;22:312-317. doi:10.1089/1549541041797931.

26. Westerman GH, Hicks MJ, Flaitz CM, Ellis RW, Powell GL. Argon laser irradiation and fluoride treatment effects on caries-like enamel lesion formation in primary teeth: an in vitro study. $A m \mathrm{~J}$ Dent. 2004;17(4):241-244.

27. Rezaei Y, Bagheri H, Esmaeilzadeh M. Effects of laser irradiation on caries prevention: J Lasers Med Sci. 2011;2(4):159-164.

28. Olivi G, Margolis FS, Genovese MD. Pediatric Laser Dentistry; A User's Guide. Chicago: Quintessence Publishing; 2011:73-76.

29. Lupi-Pégurier L, Bertrand MF, Genovese O, Rocca JP, Muller-Bolla M. Microleakage of resin-based sealants after Er:YAG laser conditioning. Lasers Med Sci. 2007; 22(3):183-188. doi:10.1007/s10103-006-0437-3.

30. Lepri TP, Souza-Gabriel AE, Atoui JA, et al. Shear bond strength of a sealant to contaminatedenamel surface: Influence of erbium:yttrium-aluminum-garnet laser pretreatment. J Esthet Restor Dent. 2008;20(6):386392. doi:10.1111/j.1708-8240.2008.00214.x.

31. Moshonov J, Stabholz A, Zyskind D, Sharlin E, Peretz B. Acidetched and erbium: yttrium aluminium garnet laser-treated enamel for fissure sealants: a comparison of microleakage. Int J Paediatr Dent. 2005;15(3):205209. doi:10.1111/j.1365-263x.2005.00624.x. 
32. Cehreli SB, Gungor HC, Karabulut E. Er,Cr:YSGG laser pretreatment of primary teeth for bonded fissure sealant application: a quantitative microleakage study. J Adhes Dent. 2006;8(6):381-386.

33. Olivi G, Genovese MD, Caprioglio C. Evidencebased dentistry on laser paediatric dentistry: review and outlook. Eur J Paediatr Dent. 2009;10(1):29-40. doi:10.1007/bf03262783.

34. Pescheck A, Pescheck B, Moritz A. Pulpotomy of primary molars with the use of a Carbon Dioxide Laser: results of a long-term in vivo study. J Oral Laser Appl. 2002;2:165-169.

35. Soares F, Varella CH, Pileggi R, Adewumi A, Guelmann M. Impact of Er,Cr:YSGG laser therapy on the cleanliness of the root canal walls of primary teeth. J Endod. 2008;34(4):474-477. doi:10.1016/j. joen.2008.02.006.

36. Olivi G, Genovese MD, Maturo P, Docimo R. Pulp capping: advantages of using laser technology. Eur $\mathrm{J}$ Paediatr Dent. 2007;8(2):89-95.

37. Odabaş ME, Bodur H, Bariş E, Demir C. Clinical, radiographic, and histopathologic evaluation of Nd:YAG laser pulpotomy on human primary teeth. J Endod. 2007;33(4):415-421. doi:10.1016/j. joen.2008.02.006.

38. Fornaini C, Rocca JP, Bertrand MF, Merigo E, Nammour S, Vescovi P. Nd:YAG and diode laser in the surgical management of soft tissues related to orthodontic treatment. Photomed Laser Surg. 2007;25(5):381-392.

39. Pakins F. Lasers in pediatric and adolescent dentistry. Dent Clin North Am. 2000;44(4):821-830.

40. Kotlow LA. Oral diagnosis of abnormal frenum attachments in neonates and infants: Evaluation and treatment of the maxillary and lingual frenum using Erbiu:YAG laser. J Pediatric Dent Care. 2004;10(3):11-
14.

41. Monteiro LS, Azevedo A, Cadilhe S, Sousa D, Faria C, Martins M. Laser treatment of vascular anomalies of oral cavity. Rev Port Stomatol Med Dent Maxillofac Surg. 2013;54:171-5.

42. Guelman M, Britto LR, Kats J. Cyclosporin-induced gingival overgrowth in a child treated with $\mathrm{CO}_{2}$ laser surgery: a case report. J Clin Pediatr Dent. 2003;27:123-6.

43. Cruz DR, Kohara EK, Ribeiro MS, Wetter NU. Effects of lowintensity laser therapy on the orthodontic movement velocity of human teeth: a preliminary study. Lasers Surg Med. 2004;35(2):117-120. doi:10.1002/lsm.20076.

44. Vaghela DJ, Sinha AA. Pulse oximetry and laser dopplerflowmetry for diagnosis of pulpal vitality. $J$ ournal of Interdiscip Dentistry. 2011;1:14-21.

45. Genovese MD, Olivi G. Laser in paediatric dentistry: patient acceptance of hard and soft tissue therapy. Eur J Paediatr Dent. 2008;9(1):13-17.

46. Fujiyama K, Deguchi T, Murakami T, Fujii A, Kushima $\mathrm{K}$, Takano-Yamamoto T. Clinical effect of $\mathrm{CO}(2)$ laser in reducing pain in orthodontics. Angle Orthod. 2008;78(2):299-303. doi:10.2319/033007-153.1.

47. Youssef M, Ashkar S, Hamade E, Gutknecht N, Lampert F, Mir M. The effect of low-level laser therapy during orthodontic movement: a preliminary study. Lasers Med Sci. 2008;23(1):27-33. doi:10.1007/ s10103-007-0449-7.

48. Kravitz ND, Kustnoto B. Soft tissue laseres in orthodontics: an overview. Am J Ortho Dentofacial Ortho. 2008;133:110-114.

49. Haytac MC, Ozcelik O. Evaluation of patient perceptions after frenectomy operations: a comparison of carbon dioxide laser and scalpel techniques. J Periodontol. 2006;77(11):1815-1819. 